\title{
Economic Burden of the Out-of-Pocket Expenses for People with Multiple Sclerosis in France
}

\author{
Olivier Heinzlef ${ }^{1,2} \cdot$ Guillaume Molinier $^{2} \cdot$ Benoît van Hille ${ }^{3}$ (D) Lise Radoszycki $\cdot$ Paul Dourgnon $^{5} \cdot$ Juliette Longin $^{3}$
}

Published online: 11 February 2020

(c) The Author(s) 2020

\begin{abstract}
Background People with chronic diseases in France frequently incur out-of-pocket expenses (OOPE) related to their medical care.

Objective The objective of this study was to evaluate OOPE incurred by people with multiple sclerosis (MS) with respect to direct non-medical and medical expenditure.

Methods Data were collected through a web-based survey using an online patient community platform (Carenity). The survey questionnaire contained 87 questions (numerical response or Likert scale) and took less than 30 min to complete. Participants rated their disability on a ten-point scale.

Results In total, 376 patients, with a mean age of 48.3 years (95\% confidence interval [CI] 47.2-49.5), participated in the survey. Participants estimated that they spent an average of $€ 127$ each month on OOPE for their MS, principally on physician consultations (mean annual expenditure of $€ 75$ by 183 participants), non-physician consultations ( $€ 358$ by 135 participants) and non-prescription medication (mean expense of $€ 67$ per pharmacy visit by 234 patients). In total, $77 \%$ of participants who needed adaptations to their home or vehicle because of their MS contributed to the cost. No obvious relationship between OOPE and self-rated disability was observed. A total of $61.4 \%$ of participants reported that they had to choose between spending money on MS care or on their family and social life.

Conclusions Most patients with MS incurred significant OOPE linked to consultations, non-prescription medications or home equipment and medical equipment. These outlays could lead to dilemmas when choosing between spending on MS care or family or social life.
\end{abstract}

\section{Introduction}

Multiple sclerosis (MS) directly affects around 100,000 people in France [1]. As the disease progresses, it is associated with poorer quality of life, greater psychological distress and loss of professional opportunities [2-4]. The

Benoît van Hille

benoit.van.hille@merckgroup.com

1 Neurology Department, Hôpital De Poissy, 10 Rue Du Champ Gaillard, 78300 Poissy, France

2 Ligue Française contre la Sclérose En Plaques (LFSEP), 40 rue Duranton, 75015 Paris, France

3 Medical Affairs Department, Merck S.A.S., 37 rue Saint Romain, 69008 Lyon, France

4 Carenity, 1 rue de Stockholm, 75008 Paris, France

5 Institut de Recherche et Documentation en Economie de la Santé (IRDES), 10 rue Vauvenargues, 75018 Paris, France multifunctional manifestations of MS require multidisciplinary management involving the hospital and community sectors, a range of healthcare professionals-from neurologists, physiotherapists and specialist MS nurses to psychologists-and social services to ensure the patient can remain as autonomous as possible at home.

Public health insurance in France is not fully comprehensive, and users generally have to pay a variable proportion of their healthcare consumption. However, patients with certain chronic diseases that are costly to manage, such as MS, are eligible for full coverage for medical healthcare consumption. Therefore, in principle, patients with MS should not have to contribute financially to their care. However, since not all types of care that patients might seek are fully covered by health insurance in France, patients may incur significant out-of-pocket expenses (OOPE), as has been reported in other disease areas [5]. In general, France has one of the lowest levels of OOPE in industrialised countries, although these have been rising over the past two decades [6]. OOPE 


\section{Key Points for Decision Makers}

Two-thirds of patients with multiple sclerosis (MS) incur out-of-pocket expenses (OOPE) associated with their pathology in spite of benefiting from ALD (Affection de Longue Durée) full reimbursement status.

The OOPE estimated by patients with MS represents 7\% of the per capita disposable household income in France

For most patients with MS, the OOPE for medications was for over-the-counter medications, whereas OOPE for consultations related to expenses related to specialists who had tariffs above ALD reimbursement levels.

may act as a barrier to patient healthcare consumption and thus be detrimental to patients' well-being. This has been demonstrated in a number of chronic diseases, including MS [7-10]. For example, two studies from the USA reported that higher patient contributions to the cost of care were associated with lower adherence to medication [11, 12]. The issue of OOPE is particularly relevant to chronic disabling diseases such as MS because patients frequently cease fulltime employment because of their disease and consequently experience a reduction in their disposable income [13].

The objective of this study was to evaluate OOPE incurred by people with MS in relation to their disease with respect to direct medical expenditure (such as medication costs) and direct non-medical expenditure (such as home adaptation for people of limited mobility).

\section{Methods}

This was a web-based survey of patients with MS conducted using an online patient community platform. Participation was voluntary. The survey was available for 8 weeks in September and October 2016. The design of the survey and exploitation of the results were supervised by a scientific committee comprising a representative from a patient advocacy group, a neurologist and a pharmaco-economist.

\subsection{Participants}

Carenity (https://www.carenity.com/) is an online patient community in which patients with chronic diseases (1200 disease-specific communities) can share their experiences, exchange information on their disease and request advice and information. Episodically, Carenity members have the opportunity to participate in online surveys concerning various aspects of disease perceptions for medical research purposes. Participation in these surveys is voluntary, and the data are shared anonymously and in aggregate form, which means participants cannot be identified. The MS patient community on Carenity currently has around 7000 members, of whom $78.9 \%$ are patients.

The present survey was available to any patient who was a member of the Carenity MS community, was aged $\geq 18$ years and was resident in France. When the survey was launched, an email was sent to all eligible members inviting them to participate, and this was followed up with weekly reminder emails during the 2 months the survey was open.

In addition, members of the French MS patient association, the Ligue Française contre la Sclérose en Plaques (LFSEP), were made aware of the survey via the Facebook page of the association and received individual emails inviting them to participate.

\subsection{Questionnaire}

The survey questionnaire was developed by Carenity in collaboration with the scientific committee and validated by the latter. The survey questionnaire contained a total of 87 questions and took, on average, less than half an hour to complete. Most of the questions were single or multiple choice to which participants provided either a numerical response or used a Likert scale. Skip patterns were used throughout the questionnaire. The study questionnaire is available in the online supplementary material.

\subsection{Data Collection}

Data collected from participants included their age, sex and information on their level of disability. As patients may not know their Expanded Disability Status Scale score [14], the reference disability measure in MS, patients self-reported their disability based on a single questionnaire used previously in surveys carried out by the LFSEP [15]. This scale assigns a grade of 1-10 according to the patient's level of disability (see Table 1).

Reimbursement status for healthcare consumption was documented. In France, the public health service does not provide comprehensive coverage of expenditure, and patients usually must pay the residual cost of care at the point of access. In total, $95 \%$ of patients subscribe to complementary health insurance, either private (subscribed to or provided by their employer) or public (so-called Universal Complementary Health Coverage [CMUC]), which may reimburse at least part of this residual cost. However, in two cases, the public health service provides $100 \%$ coverage, meaning the patient has no outlay at the point of access to care. The first is when the patient has a long-term illness identified on a limited list (ALD [Affection de Longue Durée] status), in which case they bear no costs for the care related to the listed illness; the second is when the financial resources of 
Table 1 Patient disability questionnaire

\begin{tabular}{lc}
\hline Question & Grade \\
\hline I have mild sensory symptoms & 1 \\
I have several sensory symptoms, but I can walk and run normally & 2 \\
I am significantly bothered functionally, but I can walk & 3 \\
I am functionally limited, but I can walk 500 m without help & 4 \\
I can walk 100-200 m without help or stopping & 5 \\
I always need a stick or a crutch. My activities are limited & 6 \\
I always need two sticks or crutches. My activities are limited & 7 \\
I am stuck inside but I can take a few steps hugging the wall & 8 \\
I cannot walk at all & 9 \\
I am bedridden and incapable of sitting up for more than 1 h & 10
\end{tabular}

the patient are below a specified threshold (CMUC). In principle, all patients with MS are eligible for ALD status and thus for full reimbursement. In addition, in France, healthcare costs do not vary according to whether the patient has complementary health insurance, either private or public (CMUC).

All healthcare consumption over the previous 12 months was documented. Participants were asked whether they had been hospitalised in the previous year, either for an overnight stay or for outpatient hospital visits, and, if so, how many times they had been hospitalised. They were asked to indicate whether these hospitalisations had engendered any OOPE. Participants were provided with a checklist of types of healthcare professionals (HCPs) they might have consulted and were asked which HCPs they had in fact consulted over the previous 12 months, how many times they had consulted, whether they had any OOPE for these consultations and, if so, how much. Patients were asked whether they had paid for prescription or over-the-counter (OTC) medications obtained in the pharmacy and, if so, how much they had spent. Another set of questions probed medical equipment and modifications to the home environment. OOPE were determined over a 12-month period for each expenditure item and are presented as means (95\% confidence interval $[\mathrm{CI}]$ ) and as median (range).

An ordinal rating scale was used to assess patient satisfaction with their level of reimbursement. For different categories of financial outlay, they were asked to rate whether their expenses due to MS were sufficiently reimbursed on a scale ranging from 0 (very insufficient) to 10 (fully sufficient). Scores were then categorised in three classes (score 0-3: unsatisfied; 4-7: moderately satisfied; 8-10: fully satisfied) corresponding to the three main satisfaction types.

\subsection{Analysis}

Descriptive univariate and multivariate analyses were performed using the statistical software R (3.5) and Microsoft
Excel 2013. For quantitative data, the following indicators were calculated: mean, median, $95 \% \mathrm{CI}$, minimum, maximum, quartiles and frequency ( $n[\%])$. For qualitative data, frequency distribution ( $n$ [\%]) was calculated. Multivariate analysis included subgroup analysis (type of MS, disability score) and inferential statistics: Student's test or the Wilcoxon test (quantitative data), chi-squared test or Fisher's exact test (qualitative data).

\section{Results}

\subsection{Participants}

Overall, from around 5500 patients with MS being treated, 376 patients participated in the survey. This corresponded to around $7 \%$ of the Carenity MS patient community. For these respondents, the mean age was 48.3 years (95\% CI 47.2-49.5), and four in five patients were women (Table 2). The mean age at diagnosis was 36.8 years, and the mean patient disability rating score was 4.7. Most patients had relapsing-remitting MS (RR-MS) (48\%), 26\% had secondary-progressive MS (SP-MS), 15\% had primary-progressive MS (PP-MS) and 11\% did not know their type of MS. Overall, 270 patients $(71.8 \%)$ were taking a disease-modifying treatment for their MS (89.0\% of such patients had RR-MS), principally fingolimod (18.6\%), dimethylfumarate (17.4\%) or natalizumab (11.9\%).

\subsection{Reimbursement Status for Healthcare and Access to Aid}

The vast majority of patients $(347 / 376 ; 92.3 \%)$ were registered for ALD status, giving them the right to $100 \%$ reimbursement for MS-related healthcare, and seven (1.9\%) patients were registered for CMUC status. In total, 200 patients subscribed to a complementary health insurance $(53.2 \%)$. Of note, 19 of the 29 patients who were not 
Table 2 Participant characteristics

\begin{tabular}{|c|c|}
\hline Characteristics & Patients $(N=376)$ \\
\hline \multicolumn{2}{|l|}{ Age, years } \\
\hline Mean $(95 \% \mathrm{CI})$ & $48.3(47.2-49.5)$ \\
\hline$<30$ & $26(6.9)$ \\
\hline $31-40$ & $63(16.8)$ \\
\hline $41-50$ & $118(31.4)$ \\
\hline $51-60$ & $115(30.6)$ \\
\hline$>60$ & $54(14.4)$ \\
\hline \multicolumn{2}{|l|}{ Sex } \\
\hline Male & $87(23.1)$ \\
\hline Female & 289 (76.9) \\
\hline \multicolumn{2}{|l|}{ Educational level } \\
\hline Primary & $17(4.5)$ \\
\hline Secondary & $185(49.2)$ \\
\hline Tertiary & $174(46.3)$ \\
\hline \multicolumn{2}{|l|}{ Living status } \\
\hline Living with family & 299 (79.6) \\
\hline Spouse alone & $153(40.7)$ \\
\hline Multiple members & $146(38.8)$ \\
\hline Living alone & $89(23.7)$ \\
\hline Living with friends & $6(1.6)$ \\
\hline Living in sheltered accommodation & $4(1.1)$ \\
\hline \multicolumn{2}{|l|}{ Employment status } \\
\hline Full time & $76(20.2)$ \\
\hline Part time due to MS & $57(15.2)$ \\
\hline Part time for other reasons & $14(3.7)$ \\
\hline Not working due to MS & $160(42.6)$ \\
\hline Not working for other reasons & $69(18.4)$ \\
\hline \multicolumn{2}{|l|}{ MS phenotype } \\
\hline Relapsing-remitting & $181(48.1)$ \\
\hline Secondary-progressive & $96(25.5)$ \\
\hline Primary-progressive & $57(15.1)$ \\
\hline Do not know & $42(11.2)$ \\
\hline \multicolumn{2}{|l|}{ Age at diagnosis, years } \\
\hline \multicolumn{2}{|l|}{ Mean $(95 \%$ CI $)$} \\
\hline$\leq 20$ & $36.8(35.7-37.9)$ \\
\hline $21-30$ & $97(25.8)$ \\
\hline $31-40$ & $131(34.8)$ \\
\hline $41-50$ & $83(22.1)$ \\
\hline$>50$ & $49(13.0)$ \\
\hline \multicolumn{2}{|l|}{ Patient disability rating scale score } \\
\hline Mean $(95 \%$ CI $)$ & $4.7(4.4-4.9)$ \\
\hline$\leq 2$ & $75(19.9)$ \\
\hline $3-6$ & $226(60.2)$ \\
\hline$\geq 7$ & $75(19.9)$ \\
\hline
\end{tabular}

Data are presented as mean $(95 \% \mathrm{CI})$ or $N(\%)$ unless otherwise indicated

CI confidence interval, $M S$ multiple sclerosis registered for ALD status (65.5\%) were not receiving any disease-modifying treatment.

In total, 23 patients $(6.1 \%)$ had a live-in nurse, and 90 (23.9\%) had a live-in professional non-medical carer. Of 376 patients, $141(37.2 \%)$ reported receiving some sort of aid from social services because of having MS (Fig. 1). This included administrative aid (e.g. handicapped person parking permit), pecuniary aid (e.g. disability pensions) or, less frequently, material aid (e.g. home modifications). However, more than $70 \%$ of the patients receiving aid considered the aid to be inadequate.

\subsection{Impact of Multiple Sclerosis on Earning Capacity}

Overall, 217 patients were either not working or were working part time because of their MS (57.7\%) (Table 2). This proportion was higher in patients with PP-MS (63.2\%; $p=0.0663$; not significant [NS]) or SP-MS $(68.4 \% ; p<0.05)$ than in those with RR-MS (48.1\%). In addition, 84 of the 147 patients who were working $(57.1 \%)$ had taken time off work over the last year because of their MS. This was generally paid either by social security or by the employer, although eight patients had taken unpaid leave. The median total duration of time off work was 20 days (range 1-210), and the median duration of unpaid leave was 8 days (range 7-30).

\subsection{Hospitalisations}

In total, 97 patients (25.8\%) had been hospitalised overnight because of their MS at least once in the previous year (median number of nights 5; mean 11.4; 95\% CI 8.0-14.8). In addition, 159 patients (42.3\%) had attended a hospital outpatient consultation because of their MS in the previous year (mean outpatient visits in the previous year 7.9; $95 \%$ CI 6.3-9.4; median 4).

Of the 201 patients who visited hospital (for an overnight stay or an outpatient consultation), 163 (81.1\%) reported that they needed to pay some of the associated cost. This principally related to medical procedures that were not fully reimbursed (64 patients; $31.8 \%$ ), payments for personal comfort items or private rooms (57 patients; $28.4 \%$ ) or transport to or from hospital (56 patients; 27.9\%). In addition, 42 patients $(20.9 \%)$ lost income when they went to hospital.

\subsection{Consultations}

All but eight patients had consulted a physician for their MS at least once in the previous year, and 292 patients (76.9\%) had consulted more than one type of HCP. The mean number 
Fig. 1 Aid from social services. Multiple responses were possible. Administrative aid includes disability cards or parking permits; pecuniary aid includes disability pensions or other benefits; material aid includes loan of medical equipment or home and vehicle modifications. The shaded portions of the bars indicate the proportion of respondents who considered the aid received to be inadequate

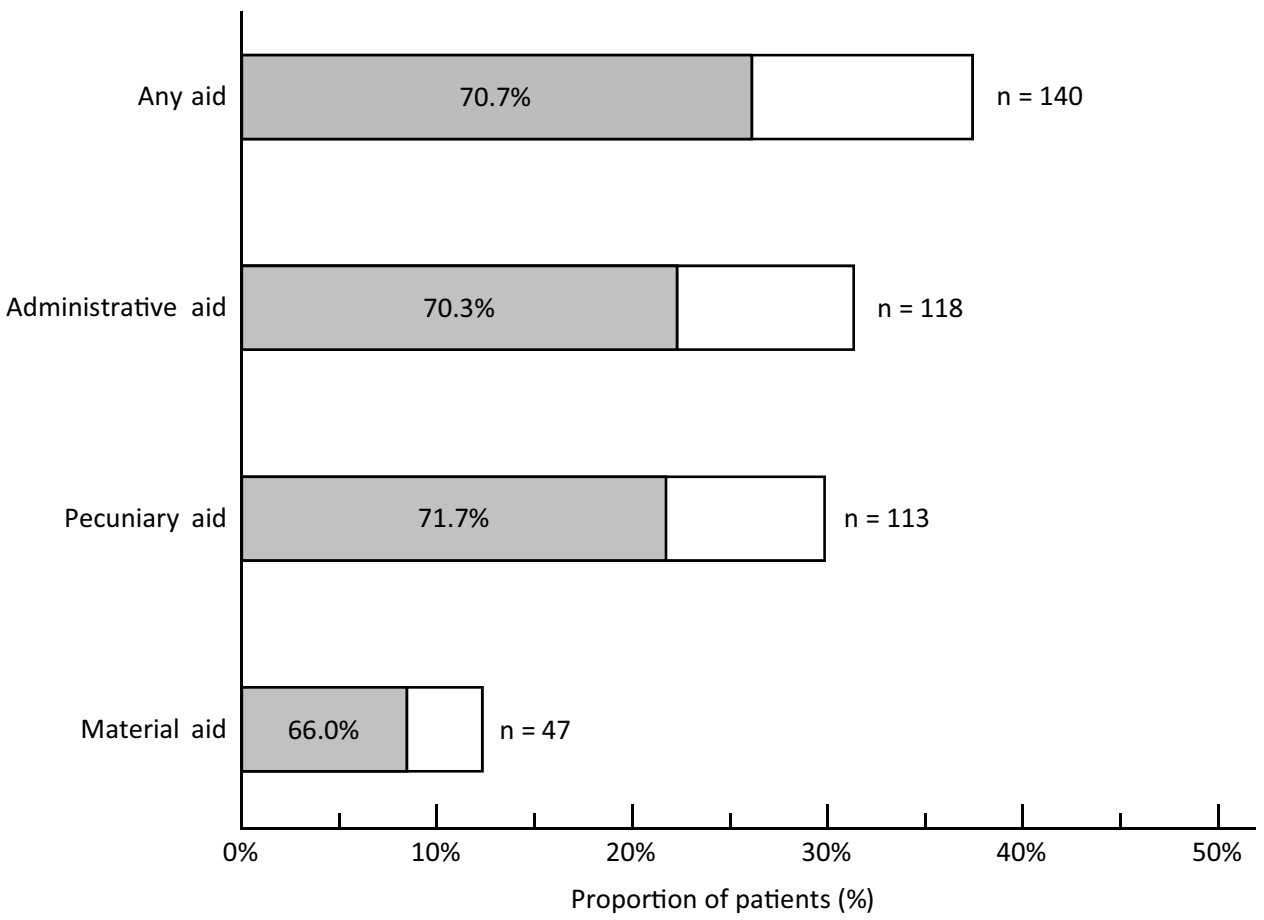

Table 3 Consultations of healthcare professionals and frequency of visits

\begin{tabular}{lc}
\hline $\begin{array}{l}\text { Number of different HCPs consulted over previ- } \\
\text { ous } 12 \text { months }\end{array}$ & Patients $(N=376)$ \\
\hline Mean $(95 \%$ CI) & $2.6(2.5-2.7)$ \\
0 visit & $8(2.1)$ \\
1 visit & $79(21.0)$ \\
2 visits & $98(26.1)$ \\
3 visits & $105(27.9)$ \\
4 and more visits & $86(22.9)$ \\
\hline
\end{tabular}

Data are presented as mean $(95 \% \mathrm{CI})$ or $N(\%)$

CI confidence interval, $\mathrm{HCP}$ healthcare professional

of types of physician consulted was 2.6 (95\% CI 2.5-2.7) (Table 3). On average, patients attended a mean of 13 physician consultations per year. The most frequently consulted specialists were neurologists, ophthalmologists and urologists (Table 3). In addition, 282 patients had consulted a paramedical HCP, and the mean number of paramedical HCPs consulted was 1.6 (95\% CI 1.5-1.8) (Table 4), principally a physiotherapist, an MS nurse, an osteopath or a psychologist (Table 5). The frequency of consultations varied markedly, from an average of 2.0 visits per year for urinary incontinence training to a mean of 62.7 physiotherapy sessions per year (Table 5).

For all physician types, some patients accrued OOPE, and this was most often the case for visits to ophthalmologists ( $49 \% ; p<0.05$ vs. $21 \%$ to physiotherapists) and GPs (44\%; $p<0.05$ vs. $21 \%$ to physiotherapists). The mean OOPE per
Table 4 Consultations of other medical-related professionals and frequency of visits

\begin{tabular}{lc}
\hline Other medical-related professional consulted & Patients $(N=376)$ \\
\hline Mean $(95 \% \mathrm{CI})$ & $1.6(1.5-1.8)$ \\
0 visit & $94(25.0)$ \\
1 visit & $120(31.9)$ \\
2 visits & $75(19.9)$ \\
3 visits & $45(12.0)$ \\
4 and more visits & $42(11.2)$ \\
\hline
\end{tabular}

Data are presented as mean $(95 \% \mathrm{CI})$ or $N(\%)$

CI confidence interval

patient who used the considered service per year was $€ 75$ (median $€ 30$ ) and, by specialist, ranged from $€ 2.5$ for internal medicine specialists to $€ 71.9$ for psychiatrists (Table 5). Most patients (77\%) also accrued OOPE from visits to other HCPs. In particular, this was the case for $89 \%$ of patients who consulted osteopaths. The mean OOPE per patient who consulted non-physicians per year was $€ 348$ (95\% CI 265.4-431.5; median $€ 100$ ), being highest for physiotherapists and psychologists (Table 3 ).

\subsection{Medical Procedures and Tests}

Overall, 336 patients (86.4\%) underwent at least one medical procedure or test related to their MS, an average of $5.6(95 \%$ CI 4.9-6.3) times a year. These procedures and tests included magnetic resonance imagery, computed tomography scans, 
Table 5 Consultations of healthcare professionals and OOPE

\begin{tabular}{|c|c|c|c|c|c|c|c|c|c|}
\hline \multirow[t]{2}{*}{ HCP type } & \multirow[t]{2}{*}{$N(\%)$} & \multirow[t]{2}{*}{ Number of visits } & \multicolumn{6}{|c|}{ Consultation with OOPE (\%) } & \multirow[t]{2}{*}{ OOPE $(€)$ in last 12 months } \\
\hline & & & $\begin{array}{l}\% \text { of consul- } \\
\text { tations with } \\
\text { OOPE }\end{array}$ & $€ 1-5$ & $€ 6-10$ & $€ 10-20$ & $€ 20-30$ & $>€ 30$ & \\
\hline GP & $259(68.9)$ & $\begin{aligned} & 7.1(6.2-8.1) \\
& 5.0(1 ; 50)\end{aligned}$ & 44 & 79 & 4 & 2 & 12 & 3 & $59.1(26.1-61.8)$ \\
\hline Neurologist & $353(93.9)$ & $\begin{array}{l}3.1(2.8-3.8) \\
2.0(1 ; 26)\end{array}$ & 25 & 47 & 13 & 10 & 10 & 20 & $52.6(23.0-61.8)$ \\
\hline Ophthalmologist & $151(40.2)$ & $\begin{array}{l}1.8(1.6-2) \\
1.0(1 ; 10)\end{array}$ & 49 & 36 & 11 & 11 & 16 & 26 & $52.6(23.8-46.8)$ \\
\hline Urologist & $91(24.2)$ & $\begin{array}{l}2.0(1.8-2.3) \\
2.0(1 ; 8)\end{array}$ & 33 & 56 & 17 & 10 & 7 & 10 & $22.6(8.0-37.1)$ \\
\hline Psychiatrist & $36(9.6)$ & $\begin{array}{l}7.5(5.3-9.4) \\
5.5(1 ; 25)\end{array}$ & 36 & 54 & 8 & 15 & 8 & 15 & $71.9(14.3-129.5)$ \\
\hline Internal medicine & $27(7.2)$ & $\begin{array}{l}3.8(2.2-5.6) \\
2.0(1 ; 15)\end{array}$ & 4 & 100 & NA & NA & NA & NA & 2.5 \\
\hline Physiotherapist & $252(67.0)$ & $\begin{array}{l}62.7(55.7-69.7) \\
48.0(1 ; 365)\end{array}$ & 21 & 56 & 4 & 5 & 9 & 26 & $196.1(77.4-489.1)$ \\
\hline MS nurse & $67(17.8)$ & $\begin{array}{l}4.4(3.2-5.5) \\
2.0(1 ; 20)\end{array}$ & 12 & 72 & 14 & NA & NA & 14 & $16.6(5.4-27.8)$ \\
\hline Osteopath & $62(16.5)$ & $\begin{array}{l}3.2(2.4-4.0) \\
2.0(1 ; 20)\end{array}$ & 89 & NA & NA & 17 & 9 & 74 & $155.2(107.6-202.8)$ \\
\hline Psychologist & $59(15.7)$ & $\begin{array}{l}8.9(6.6-11.2) \\
6.0(1 ; 35)\end{array}$ & 42 & NA & 9 & NA & 5 & 86 & $528.4(304.6-752.1)$ \\
\hline UI training & $50(13.3)$ & $\begin{aligned} & 2.5(1.9-3.2) \\
& 2.0(1 ; 10)\end{aligned}$ & 20 & 60 & NA & 20 & 10 & 10 & $19.7(6.5-32.8)$ \\
\hline Occupational therapist & $48(12.8)$ & $\begin{array}{l}12.5(7.9-17.1) \\
6.5(1 ; 40)\end{array}$ & 8 & 25 & 50 & NA & NA & 25 & $56.8(0-118)$ \\
\hline Sport medicine & $35(9.3)$ & $\begin{array}{l}50.4(26.2-74.6) \\
24.5(1 ; 365)\end{array}$ & 42 & 18 & 18 & 18 & 18 & 28 & $194.8(53.9-335.7)$ \\
\hline Any HCP & $372(98.9)$ & $\begin{array}{l}66.0(57.6-74.4) \\
27(1 ; 730)\end{array}$ & 63 & 5 & 4 & 9 & 8 & 74 & $348.4(265.4-431.5)$ \\
\hline
\end{tabular}

Data are presented as $N(\%)$, mean (95\% confidence interval) or median (minimum; maximum) unless otherwise stated. Only HCPs consulted by more than 25 patients were considered

$G P$ general practitioner, $H C P$ healthcare professional, $M S$ multiple sclerosis, $N A$ not applicable, $O O P E$ out-of-pocket expenses $U I$ urinary incontinence

echography, electrocardiogram and blood tests. The procedures were generally fully reimbursed, and only 51 patients (15.2\%) reported OOPE. The mean annual expense was $€ 192.1$ (95\% CI 108.5-275.6; median €58). However, five of these 51 patients reported OOPE in excess of $€ 500$.

\subsection{Medication}

Of the 376 included patients, 327 (87.0\%) reported no outlay on prescription medication for MS when they collected this from the pharmacy. The remaining 49 patients, who included 45 patients registered for full reimbursement based on ALD status, spent an average of $€ 62.6$ (95\% CI 39.0-86.1; median $€ 32)$ on medication at each pharmacy visit.

In addition, 234 patients (62\%) had purchased OTC medication for their MS during the previous month, which was entirely at their own expense. The mean cost of these medications was €66.2 (95\% CI 39.0-86.1; median €32) per visit, and 38 patients spent over $€ 100$ at each visit on OTC medication.

Assuming that the costs patients incurred for OTC medication were similar each month to those reported for 1 month (€66.6; 95\% CI 39.0-83.3), the total mean annual OOPE on OTC medications for patients using such support would be $€ 794$ (95\% CI 699-890; median €420).

\subsection{Specialised Residential Accommodation}

In total, 75 patients (19.9\%) had stayed in specialised residential accommodation over the previous 12 months, principally in functional rehabilitation clinics (75 patients). Of these 75 patients, $12(16.0 \%)$ had to pay for all (one patient) 
or part (11 patients) of the residential stay costs, amounting to a mean OOPE of $€ 331$ for these patients. Three patients spent over $€ 500$ for these costs.

\subsection{Home Care and Services}

Overall, 240 patients (64\%) had benefited from home care or services in the previous 12 months, with $41 \%$ benefiting from multiple services. The services most frequently used were ambulance or medical taxis, nurse visits and domestic home care (Table 6). Domestic home care, physiotherapist home visits and meal deliveries were used at least weekly, and the other services were used less frequently. The only services for which the patient paid more often than ambulance/taxi were domestic healthcare, childcare help and meal delivery (all $p<0.05$ vs. ambulance/taxi).

\subsection{Home Equipment and Medical Equipment}

Walking aids and wheelchairs were the most frequently purchased medical equipment, and these were completely reimbursed for over half of the patients who purchased them (Fig. 2). The items that incurred OOPE most often were adaptation of their home (e.g. installation of ramps or rails) or of their vehicle ( $p<0.05$ for both vs. walking aid).

\subsection{Impact of Disability on Out-of-Pocket Expenses}

Except for medication costs, which were highest in the most disabled patients (disability grades 7-10), OOPE for patients who used the considered medical services did not vary markedly with disability (no statistical difference between disability grades $0-2$ and 7-10) (Table 7).

\subsection{Perceptions of Reimbursement}

The mean score for satisfaction with reimbursement was 6.7 (95\% CI 6.4-7.0; median 8). The proportion of patients unsatisfied with the level of reimbursement (score $0-3$ ) was $18.4 \%$, and the proportion of those who were totally satisfied (score $8-10$ ) was $51.1 \%$. The proportion of unsatisfied patients tended to be higher in those without any complementary health insurance (27\%) than in those benefiting from ALD status (18\%; NS) or with voluntary complementary insurance (19\%; NS) and higher in those with a high level of disability (grade $\geq 7: 21 \%$ ) than in those with a low level (grade $\leq 2: 10 \%$; NS). The types of expenses that patients considered should be better reimbursed were home care $(47.6 \%$ of respondents), modifications to the home (44.9\%), medical equipment (such as walking aids) (25.5\%), stays in specialised residential accommodation (17.0\%) and consultations $(16.0 \%)$.

When asked to estimate the level of their OOPE by month, in a specific question, patients claimed to spend on average $€ 127$ (95\% CI 95-159; median 25). Overall, 73.7\% of patients considered that their purchasing power had decreased since their diagnosis of MS (31.9\% a little; $22.3 \%$ a lot; $19.4 \%$ a huge amount). In addition, $35.6 \%$ of patients reported that they had sometimes had to make choices between spending money on their MS care and spending on their family and social life, and $25.8 \%$ reported that they frequently had to make such choices.

\section{Discussion}

The objective of this study was to evaluate OOPE incurred by people with MS in relation to their disease. Patients estimated that they spent an average of $€ 127$ each month on OOPE for their MS, corresponding to around $€ 1500$ per year. This represents around $7 \%$ of the per capita disposable

Table 6 Home care and services

\begin{tabular}{lccccccc}
\hline Service type & $N$ & \multicolumn{2}{l}{ Frequency of use } & Any OOPE \\
\cline { 3 - 6 } & & & Every day & Once a week & Once a month & $\begin{array}{l}1-6 \\
\text { times a } \\
\text { year }\end{array}$ \\
\hline Ambulance/taxi & $168(44.7)$ & 11 & 14 & 24 & 51 & $20(11.9)$ \\
Nurse visit & $127(33.8)$ & 9 & 13 & 27 & 51 & $10(7.9)$ \\
Domestic home care & $112(29.8)$ & 28 & 62 & 5 & 4 & $80(71.4)$ \\
Physiotherapist visit & $63(16.8)$ & 32 & 60 & 3 & 5 & $5(7.9)$ \\
Social service visitor & $33(8.8)$ & 3 & 9 & 9 & 79 & $2(6.1)$ \\
Childcare help & $9(2.4)$ & 33 & 33 & 11 & 23 & $6(66.7)$ \\
Meal delivery & $6(1.6)$ & 50 & 50 & - & - & $4(66.7)$ \\
\hline
\end{tabular}

Data are presented as \% or $N(\%)$

$O O P E$ out-of-pocket expenses 
Fig. 2 Medical equipment and modifications to the home environment. The dark shaded portion of each bar indicates the proportion of patients who incur out-of-pocket expenses for the different types of equipment

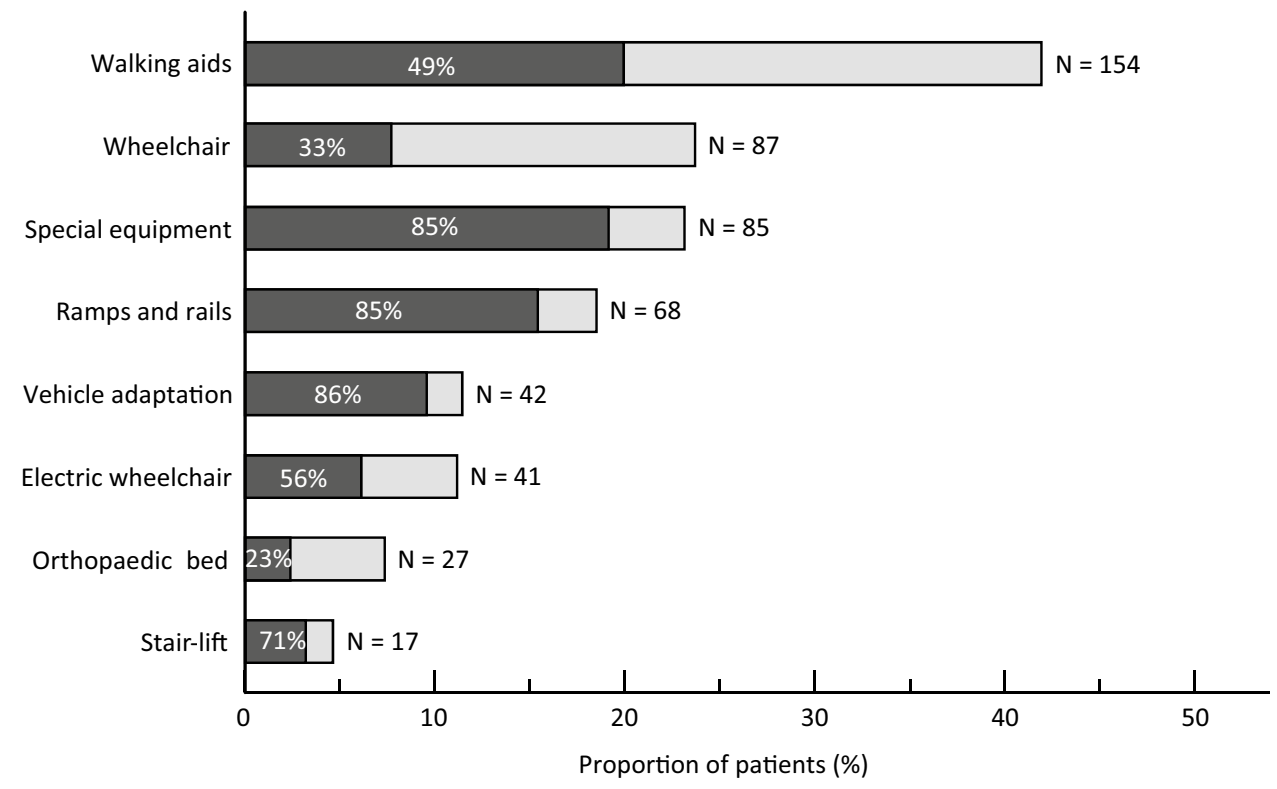

household mean income in France, which was $€ 21,415$ in 2015 [16]. For comparison, the annual direct per capita medical costs of MS to public health insurance in France have been estimated to range from $€ 18,000$ to 33,000 in 2016 , depending on the extent of disability [17]. Around twothirds of patients had OOPE associated with consultations and medication. In addition, patients reported that adaptations of the home environment and medical equipment were generally poorly reimbursed, although the associated OOPE have not been quantified. No clear relationship between the extent of OOPE and disability was observed.

This survey was performed in a population participating in an online patient community forum dedicated to MS. We do not expect this population to be entirely representative of all patients with MS in France, and this limitation should be borne in mind when interpreting these findings. Although the age distribution of participants was comparable to that of all patients [1], women were more represented than men (sex ratio female:male of 2.36 in the French MS population [1] and 3.32 in the present survey), which is a characteristic of online users willing to share experiences related to their disease. In addition, participants were better educated than the general French population, with around half the participants having attended higher education, which is almost twice as high as the rate in an age-matched sample of the general population [18]. Participants in MS-specific online patient communities are likely to be more informed about MS and more inquisitive about sources of information. In the context of this survey, it is possible that participants are more aware of the aid to which they are entitled and thus may have lower OOPE than patients with MS in general.

Surveys of such communities provide an opportunity to collect information on perceptions of healthcare provision and use from relatively large samples, which would be difficult to collect in an equivalent timeframe using more traditional methods [19]. The information provided by members of these online patient communities represents a new resource for identifying and understanding how health products are used and perceived in the real world, for developing new assessment tools for patient-reported outcomes and for fostering sociological research into health-related issues.

In principle, patients with MS are eligible for ALD status that gives them access to full insurance coverage for healthcare consumption with no need for pecuniary outlay at the point of access to care. In France, healthcare costs do not vary according to complementary health insurance. ALD and CMU criteria were not intended to be used as variables for the comparisons. In practice, $92 \%$ of participants in this survey were indeed registered for ALD status. Most of the patients without ALD status were not taking a diseasemodifying treatment for MS. The proportion of participating patients registered for ALD was higher than that observed for all patients with MS in France (83.3\%) [1].

In spite of having ALD status, most patients reported OOPE related to hospitalisations, consultations and medication costs. Although, for most patients, the OOPE for medication corresponded to OTC medication, which, by definition, is not reimbursed by social security, a minority of patients also had OOPE for prescription medications, amounting to an average of $€ 63$ per year, which may correspond to approved medications that are not reimbursed. The OOPE for consultations are probably because specialists in France are free to set their consultancy fees above the tariffs reimbursed by the public health insurance, the difference being payable by the patient. Consultations with psychiatrists or psychologists were particularly associated 
Table 7 Overview of annual OOPE $(€)$ as a function of disability

\begin{tabular}{|c|c|c|c|c|}
\hline & Medication & Consultations & Procedures/tests & Residential care \\
\hline Patients using, $N(\%)$ & $376(100)$ & $372(98.9)$ & $336(89.4)$ & 75 (19.9) \\
\hline Patients with OOPE, $N(\%)$ & $238(63.3)$ & $235(62.5)$ & $51(13.6)$ & $12(3.2)$ \\
\hline \multicolumn{5}{|l|}{ All patients with OOPE } \\
\hline$N(\%)$ & $238(63.3)$ & $235(62.5)$ & $51(13.6)$ & $12(3.2)$ \\
\hline Mean & 926 & 348 & 192 & 331 \\
\hline Median & 420 & 100 & 58 & 50 \\
\hline$Q 1 ; Q 3$ & $420 ; 1020$ & $30 ; 386$ & $40 ; 200$ & $35 ; 575$ \\
\hline Minimum; maximum & $12 ; 8400$ & $3 ; 5928$ & $1 ; 1500$ & $0 ; 1500$ \\
\hline \multicolumn{5}{|l|}{ Disability grade $0-2$} \\
\hline$N$ & $46(12.2)$ & $46(12.2)$ & $14(3.7)$ & $1(0.3)$ \\
\hline Mean & 960 & 379 & 169 & 1500 \\
\hline Median & 420 & 101 & 50 & 1500 \\
\hline$Q 1 ; Q 3$ & $420 ; 1,020$ & $25 ; 404$ & $25 ; 180$ & 1,$500 ; 1500$ \\
\hline Minimum; maximum & $120 ; 6000$ & $3 ; 5928$ & $1 ; 1000$ & 1,$500 ; 1500$ \\
\hline \multicolumn{5}{|l|}{ Disability grade $3-4$} \\
\hline$N$ & $59(15.7)$ & $58(15.4)$ & $14(3.7)$ & $4(1.1)$ \\
\hline Mean & 968 & 277 & 223 & 35 \\
\hline Median & 420 & 94 & 100 & 40 \\
\hline$Q 1 ; Q 3$ & $420 ; 1020$ & $41 ; 313$ & $52 ; 195$ & $30 ; 45$ \\
\hline Minimum; maximum & $120 ; 6840$ & $3 ; 2500$ & $1 ; 1000$ & $0 ; 60$ \\
\hline \multicolumn{5}{|l|}{ Disability grade $5-6$} \\
\hline$N$ & $84(22.3)$ & $80(21.3)$ & $15(4.0)$ & $2(0.5)$ \\
\hline Mean & 711 & 371 & 200 & 275 \\
\hline Median & 420 & 118 & 50 & 275 \\
\hline$Q 1 ; Q 3$ & $420 ; 720$ & $30 ; 501$ & $50 ; 177$ & $163 ; 388$ \\
\hline Minimum; maximum & $12 ; 4800$ & $5 ; 2765$ & $30 ; 1500$ & $50 ; 500$ \\
\hline \multicolumn{5}{|l|}{ Disability grade $7-10$} \\
\hline$N$ & $49(13.0)$ & $51(13.6)$ & $8(2.1)$ & $5(1.3)$ \\
\hline Mean & 1211 & 367 & 163 & 356 \\
\hline Median & 720 & 97 & 40 & 50 \\
\hline$Q 1 ; Q 3$ & $420 ; 1500$ & $25 ; 331$ & $20 ; 103$ & $20 ; 800$ \\
\hline Minimum; maximum & $48 ; 8400$ & $3 ; 3915$ & $16 ; 900$ & $12 ; 900$ \\
\hline
\end{tabular}

Other identified expenses for which OOPE were not quantified (time off work, hospitalisations, home care/ services, home equipment); difference in OOPE between disability grades 0-2 and 7-10; non-parametric Wilcoxon test: $p=0.4557$

$O O P E$ out-of-pocket expenses, $Q$ quarter with a high level of OOPE. In addition, certain paramedical professions, such as osteopaths, who are consulted by significant numbers of patients, are not reimbursed by public health insurance. The OOPE for hospitalisation was accounted for in part by personal comfort items, which are always charged to the patient, and for certain medical procedures that are not fully reimbursed.

As well as specific medical expenditure, major areas that generate OOPE in MS include aid at home, professional carers or home help, costs of adaptation of the home for people with disabilities, transport from home to medical consultations and for expensive items such as powered mobility scooters or orthopaedic beds. Although the OOPE for this type of expenditure were not quantified in this survey, patients stated these were the types of expenditure they would like to see better reimbursed. Some of these services are, in principle, provided by social services rather than the healthcare system per se, and the findings suggest that communication between the two could be optimised to provide a seamless package of support for people qualifying for ALD status for MS or other chronic diseases.

Our findings can be compared with those from a recent study of OOPE for MS care in Canada [20], which reported 
that $44 \%$ of respondents had OOPE for medication costs, $22.8 \%$ for assistive devices, $19.0 \%$ for rehabilitation therapy and $7.9 \%$ for home-care services. Despite important differences in the organisation of healthcare between Canada and France, these findings are of the same order of magnitude. In contrast, in the USA, where universal public health insurance does not exist, $57 \%$ of patients with MS incur OOPE $\geq \$$ US50 at each pharmacy delivery of medication, and $12 \%$ incur OOPE of $\geq \$$ US250 [21]. This US study, as well as earlier studies reviewed elsewhere [7], indicated that high OOPE for medication is associated with poor adherence.

Although most patients (51\%) considered the level of reimbursement for their MS care totally satisfactory, a significant minority were not satisfied at all. Regardless of the expressed satisfaction level, $74 \%$ considered that their spending power had diminished since they were diagnosed with MS, and $61 \%$ stated that they had to choose whether to spend money on MS care or on family and social life. This suggests the financial impact of OOPE for MS care is significant. In addition, 58\% of respondents had either given up working or reduced their working hours because of their disease. In contrast, only $37 \%$ were receiving any form of disability allowance, and $71 \%$ of those who received the allowance considered it to be inadequate.

The study has several limitations, including the potential lack of representativeness of the study population discussed earlier in this section. The information on OOPE over the previous year was obtained from the volunteer participants and may be susceptible to underrepresentation of patients with no OOPE, to perception or social desirability bias and to recall amnestic error [19]. However, the quantitative estimations were restricted to expenses (medications and consultations, medical tests and procedures and residential stays) that should have a standard recurring cost. Nevertheless, we could not verify the accuracy of the reported OOPE. This would only be possible through a dedicated micro-costing study, which would have its own inherent biases and limitations. We did not evaluate OOPE incurred during hospital visits; these are not documented because, in the French healthcare system, patients do not pay for these consultations or medicines. We also made no attempt to quantify OOPE related to home care, services and adaptation, even though these were the principal types of expense with which patients were dissatisfied. It would be important to attempt to measure these OOPE in a future study to appreciate the extent of the problem. There may also have been some misunderstanding relating to wording.

\section{Conclusion}

The results of this survey indicate that, in spite of being eligible for full coverage of healthcare resource consumption, patients with MS in France still have significant OOPE related to direct medical care and also incur OOPE related to home care and services, which are necessary but not covered by health insurance. These OOPE affect the ability of patients to make free choices as to how to spend their money. Closer coordination between public health insurance and social services is needed to ensure that patients with MS receive the aid to which they are entitled and are exposed to the lowest possible financial burden from their disease.

Acknowledgements The authors are grateful to Olivier Chevreuil, who refined the manuscript.

Author Contributions $\mathrm{OH}, \mathrm{GM}, \mathrm{BvH}, \mathrm{LR}, \mathrm{PD}$ and $\mathrm{JL}$ were involved in the conception and design of the study. LR conducted the web-based survey using the Carenity patient platform. OH, GM and PD were the members of the scientific committee. A medical writer under the supervision of $\mathrm{BvH}$ wrote the first draft of the manuscript. $\mathrm{OH}, \mathrm{GM}$, $\mathrm{BvH}, \mathrm{LR}, \mathrm{PD}$ and JL contributed to data analysis and made significant contributions to the manuscript.OH, GM, BvH, LR, PD and JL read and approved the final manuscript.

Data Availability Statement The datasets analysed during the current study are not publicly available so as to maintain participant confidentiality, but consolidated data are available from the corresponding author on reasonable request. The questionnaire sent to patients through the Carenity community platform is available as online supplementary material.

\section{Compliance with Ethical Standards}

Funding The study and the writing of the manuscript were funded by Merck S.A.S

Conflict of interest Merck KGaA, Darmstadt, Germany, markets drugs for MS. Benoît van HILLE and Juliette LONGIN are employees of Merck S.A.S., an affiliate of Merck KGaA, Darmstadt, Germany. Lise RADOSZYCKI is an employee of Carenity. Olivier HEINZLEF, Guillaume MOLINIER and Paul DOURGNON are independent experts who received fees for participating on the scientific committee.

Ethics approval Ethics approval was not required as the study was a satisfaction survey. However, the scientific committee included a physician, a health economist and a patient association representative to deal with scientific and ethical questions.

Informed consent Informed consent was obtained from all individual participants of the Carenity web platform included in the study. 
Open Access This article is licensed under a Creative Commons Attribution-NonCommercial 4.0 International License, which permits any non-commercial use, sharing, adaptation, distribution and reproduction in any medium or format, as long as you give appropriate credit to the original author(s) and the source, provide a link to the Creative Commons licence, and indicate if changes were made. The images or other third party material in this article are included in the article's Creative Commons licence, unless indicated otherwise in a credit line to the material. If material is not included in the article's Creative Commons licence and your intended use is not permitted by statutory regulation or exceeds the permitted use, you will need to obtain permission directly from the copyright holder.To view a copy of this licence, visit $\mathrm{http} / / /$ creativecommons.org/licenses/by-nc/4.0/.

\section{References}

1. Foulon S, Maura G, Dalichampt M, Alla F, Debouverie M, Moreau T, Weill A. Prevalence and mortality of patients with multiple sclerosis in France in 2012: a study based on French health insurance data. J Neurol. 2017;264(6):1185-92.

2. Clavelou P, Auclair C, Taithe F, Gerbaud L. Quality of life in multiple sclerosis. Rev Neurol. 2009;165(Suppl 4):S123-128.

3. Kern S, Schrempf W, Schneider H, Schultheiss T, Reichmann H, Ziemssen T. Neurological disability, psychological distress, and health-related quality of life in MS patients within the first three years after diagnosis. Mult Scler (Houndmills, Basingstoke, Engl). 2009;15(6):752-8.

4. Raggi A, Covelli V, Schiavolin S, Scaratti C, Leonardi M, Willems M. Work-related problems in multiple sclerosis: a literature review on its associates and determinants. Disabil Rehabil. 2016;38(10):936-44.

5. Sevilla-Dedieu C, Kovess-Masfety V, Gilbert F, Vilagut G, Koenig HH, Bruffaerts R, Haro JM, Alonso J. Mental health care and out-of-pocket expenditures in Europe: results from the ESEMeD project. J Ment Health Pol Econ. 2011;14(2):95-105.

6. Rice T, Quentin W, Anell A, Barnes AJ, Rosenau P, Unruh LY, van Ginneken E. Revisiting out-of-pocket requirements: trends in spending, financial access barriers, and policy in ten high-income countries. BMC Health Serv Res. 2018;18(1):371.

7. Menzin J, Caon C, Nichols C, White LA, Friedman M, Pill MW. Narrative review of the literature on adherence to disease-modifying therapies among patients with multiple sclerosis. J Manag Care Pharm. 2013;19(1 Suppl A):S24-S40.
8. Heidari P, Cross W, Crawford K. Do out-of-pocket costs affect medication adherence in adults with rheumatoid arthritis? A systematic review. Semin Arthritis Rheum. 2018;48(1):12-211.

9. Mann DM, Woodward M, Muntner P, Falzon L, Kronish I. Predictors of nonadherence to statins: a systematic review and metaanalysis. Ann Pharmacother. 2010;44(9):1410-21.

10. Polonsky WH, Henry RR. Poor medication adherence in type 2 diabetes: recognizing the scope of the problem and its key contributors. Patient Prefer Adher. 2016;10:1299-307.

11. Dor A, Lage MJ, Tarrants ML, Castelli-Haley J. Cost sharing, benefit design, and adherence: the case of multiple sclerosis. Adv Health Econ Health Serv Res. 2010;22:175-93.

12. Lafata JE, Cerghet M, Dobie E, Schultz L, Tunceli K, Reuther J, Elias S. Measuring adherence and persistence to disease-modifying agents among patients with relapsing remitting multiple sclerosis. J Am Pharm Assoc. 2008;48(6):752-7.

13. Landfeldt E, Castelo-Branco A, Svedbom A, Lofroth E, Kavaliunas A, Hillert J. Personal income before and after diagnosis of multiple sclerosis. Value Health. 2018;21(5):590-5. https://doi. org/10.1016/j.jval.2017.09.021.

14. Kurtzke JF. Rating neurologic impairment in multiple sclerosis: an expanded disability status scale (EDSS). Neurology. 1983;33(11):1444-522.

15. Rabin R, de Charro F. EQ-5D: a measure of health status from the EuroQol Group. Ann Med. 2001;33(5):337-43.

16. Albertini H, Altéa MJ, Besbes M, Betti C, Caste F, FaudonLachant S, et al. INSEE: Tableaux de l'économie française. Édition 2018. Insee Références; 2018.

17. Lebrun-Frenay C, Kobelt G, Berg J, Capsa D, Gannedahl M. New insights into the burden and costs of multiple sclerosis in Europe: results for France. Eur Mult Scler Platf Mult Scler. 2017;23(2 Suppl):65-77. https://doi.org/10.1177/1352458517708125.

18. INSEE: Niveau d'éducation de la population. In: France, portrait social, édition 2016. Paris: Insee Références; 2016, pp 192-193.

19. Ravoire S, Lang M, Perrin E. Advantages and limitations of online communities of patients for research on health products. Therapie. 2017;72(1):135-43.

20. Obembe AO, Goldsmith CH, Simpson LA, Sakakibara BM, Eng JJ. Support service utilization and out-of-pocket payments for health services in a population-based sample of adults with neurological conditions. PLoS ONE. 2018;13(2):e0192911.

21. Starner CI, Alexander GC, Bowen K, Qiu Y, Wickersham PJ, Gleason PP. Specialty drug coupons lower out-of-pocket costs and may improve adherence at the risk of increasing premiums. Health Aff (Proj Hope). 2014;33(10):1761-9. 